\title{
Bilateral versus unilateral interlaminar approach for bilateral decompression in patients with single-level degenerative lumbar spinal stenosis: a multicenter retrospective study of 175 patients on postoperative pain, functional disability, and patient satisfaction
}

\author{
Hugo F. den Boogert, MD, Joost C. Keers, PhD, ${ }^{2}$ D. L. Marinus Oterdoom, MD, ${ }^{1,3}$ and \\ Jos M. A. Kuijlen, MD, PhD'
}

\begin{abstract}
1Department of Neurosurgery, University Medical Center Groningen; and ${ }^{2}$ Van Swieten Scientific Institute and ${ }^{3}$ Department of Neurosurgery, Martini Hospital Groningen, The Netherlands
\end{abstract}

\begin{abstract}
OBJECT The bilateral and unilateral interlaminar techniques for bilateral decompression both demonstrate good results for the treatment of degenerative lumbar spinal stenosis (DLSS). Although there is some discussion about which approach is more effective, studies that directly compare these two popular techniques are rare. To address this shortcoming, this study compares postoperative functional disability, pain, and patient satisfaction among patients with single-level DLSS who underwent bilateral decompression using either a bilateral or unilateral approach.
\end{abstract}

METHODS This retrospective study included patients who underwent operations between November 1, 2009, and October 1, 2011. These patients underwent single-level bilateral decompressive surgery using either the bilateral or unilateral interlaminar approach at one of 5 participating hospitals. Exclusion criteria included previous lumbar surgery, additional disc surgery, and spondylolisthesis requiring fusion surgery. Primary outcome measures included bodily pain (as reported using the visual analog scale [VAS]), the Roland-Morris Disability Questionnaire (RMDQ), and the Oswestry Disability Index (ODI). In addition, reductions in leg and back symptoms and the patient's general evaluation of the procedure were queried. Finally, patient satisfaction and surgical parameters were evaluated. Questionnaires were sent to each patient's home, and electronic patient files were used to collect the data.

RESULTS One hundred and seventy-five patients returned the questionnaire (74.4\% response rate; 68 and 107 patients who underwent the bilateral or unilateral approach, respectively). Mean age at surgery was 68 years (range 34-89 years), and the mean follow-up period was 14.2 months (range 3.3-27.4 years). There were no significant differences in ODI ( 20.3 vs 22.6 for the bilateral and unilateral approaches, respectively), RMDQ ( 3.99 vs 4.8, respectively), or pain scores between treatment groups. Back symptoms were reduced in $74.8 \%$ (bilateral: $74.6 \%$ vs unilateral: $75 \%$; not significant), and leg symptoms in $80.6 \%$ of the patients (bilateral: $73.1 \%$ vs unilateral: $85.4 \% ; p=0.048$ ). In total, $72.1 \%$ (bilateral) and $80.0 \%$ (unilateral) of patients reported good overall treatment results $(p=0.226)$. Significantly more patients in the unilateral group reported a better overall satisfaction with the procedure $(82.1 \%$ vs $69.1 \% ; p=0.047)$.

CONCLUSIONS There were no differences in postoperative functional disability and pain between the surgical techniques. The significant differences in patient satisfaction and reduction in leg symptoms were unrelated to surgical technique. The overall treatment results were satisfactory. Both techniques are safe and effective options for treating patients with single-level DLSS.

http://thejns.org/doi/abs/10.3171/2014.12.SPINE13994

KEY WORDS decompression; interlaminar; lumbar stenosis; unilateral; bilateral; patient satisfaction; pain; disability

ABBREVIATIONS DLSS = degenerative lumbar spinal stenosis; ODI = Oswestry Disability Index; RMDQ = Roland-Morris Disability Questionnaire; SF-20 = Short Form Health Survey-20; VAS = visual analog scale.

SUBMITTED November 10, 2013. ACCEPTED December 30, 2014.

INCLUDE WHEN CITING Published online June 19, 2015; DOI: 10.3171/2014.12.SPINE13994.

DISCLOSURE The authors report no conflict of interest concerning the materials or methods used in this study or the findings specified in this paper. 
$\mathrm{T}$ HE prevalence of degenerative lumbar spinal stenosis (DLSS) is rising because of aging populations, and the condition can lead to serious functional disability and a decrease in quality of life among these patients. ${ }^{8,18,20,44,53,61}$ DLSS is currently the most common indication for spinal surgery in patients older than 65 years, ${ }^{13,19,20,53,56}$ and several studies have shown better surgical results over more conservative therapies. ${ }^{2,5,6,10,25,27,38,63}$ However, open conventional laminectomy has been criticized because of its limited success rate ${ }^{60}$ and potential for negative side effects, such as the increased risk of postoperative instability and the subsequent need for secondary fusion surgery; this is again associated with additional risks and costs, ${ }^{15,23,28,35,36,52}$ and also persistent postoperative back pain due to prolonged muscle retraction. ${ }^{1,39,54}$ As a result of these potential side effects, the development of less invasive techniques was initiated. ${ }^{9}$

In 1988, Young et al. introduced microscope-assisted bilateral laminotomy. ${ }^{64}$ In 1999, a less invasive unilateral approach was introduced for bilateral decompression. ${ }^{62}$ Using this technique, the paraspinal muscles are unilaterally mobilized, thereby preserving the functional integrity of the contralateral muscles and inter- and supraspinous ligaments. These less invasive lumbar microsurgical decompressive techniques have shown good clinical results and, at the same time, have reduced the chance of postoperative instability. ${ }^{9,22,34,42,43,46,58,59,62,64}$

However, whether or not these two techniques are equal to each other in terms of important postoperative clinical outcomes and certain surgical parameters remains unclear. A large, preferably prospective, randomized study that compares only these two techniques is lacking; however, one needs to be critical when questioning the real benefits of such a study if both treatment options demonstrate similar and promising results.

To address this question, we conducted this multicenter retrospective study to compare the bilateral and unilateral approaches for treating patients with single-level DLSS in terms of each patient's postoperative pain, functional disability, symptom reduction and satisfaction, and certain surgical parameters.

\section{Methods}

Patients who underwent bilateral decompression for single-level DLSS between November 2009 and October 2011 at one of 5 participating clinics were eligible for inclusion in this retrospective study. Other inclusion criteria were radiological evidence of stenosis on MRI or CT, no history of lumbar surgery, and use of the unilateral or bilateral approach as described in the next section. $\mathrm{Pa}-$ tients who underwent additional surgery (e.g., lumbar disc surgery, instrumentation) were excluded. Because of the possible correlation with surgical outcomes, patients with spondylolisthesis - but who did not need any additional fusion surgery-were not excluded. ${ }^{37}$ Neurosurgeons from the participating top clinical neurosurgical center and its satellite hospital only performed the unilateral technique. At the other 3 hospitals (a university hospital with 2 satellite hospitals), only the bilateral interlaminar procedure was performed. All hospitals are high-volume spine cen- ters, and all participating neurosurgeons had more than 3 years of surgical experience.

The participating clinics together provide all neurosurgical care in the northern part of the Netherlands, thereby increasing the chance of a geographically homogeneous research population. There are no signs that the patients chose a specific hospital because of the surgical technique, so allocation to a technique was random.

The medical ethics committees of the participating centers oversaw the entire study protocol, and written approval was obtained to perform the proposed study. Data were obtained using electronic patient files and patient-administered questionnaires. Questionnaires were sent to the patients, along with a letter explaining the purpose of the study and the role of the participants; patients provided informed consent by sending back the completed questionnaire. After 3 weeks, all nonrespondents were contacted in order to increase the response rate.

\section{Surgical Techniques}

Positioning of the patient and anesthesia administration were performed according to the preferences of the specific institutions. For both surgical procedures, the correct level of surgery was confirmed using intraoperative imaging, and a median linear incision was made to expose the spine. All surgeries were performed in a standardized manner.

\section{Bilateral Approach}

The paraspinous muscles were stripped on both sides of the spinous process. The supra- and interspinous ligaments as well as a rim of bone from the caudal aspect of the cranial lamina and the cranial aspect of the caudal lamina were removed, thereby creating a larger interlaminar space. The ligamentum flavum was removed bilaterally, and the bilateral spinal recess was subsequently opened by undercutting minimal portions of the medial facet joints.

\section{Unilateral Approach}

The paraspinous muscles were stripped on one side without removing the supra- and interspinous ligaments. The unilateral superior and inferior laminae and the medial aspect of the ipsilateral facet joint were reduced, and the ligamentum flavum was removed. When the dural sac and ipsilateral recess were sufficiently decompressed, the medial portions of the laminae were undercut to allow contralateral decompression. By slightly turning the operating table and angling the microscope, a cross-over pathway-which ran dorsally over the dural sac - could be visualized, and as much ligamentum flavum and hypertrophic bone as possible was removed from the contralateral side.

During either procedure, a high- or low-vacuum drain was inserted in most cases. Dural tears (a possible complication of either technique) were repaired using Ti-Cron sutures or closed using TachoSil (Nycomed). Early full mobilization without a brace was encouraged. When dural tears did occur, a few days of postoperative bed rest was prescribed in most cases. 


\section{Baseline and Outcome Assessments \\ Patient Characteristics}

Demographic data and preoperative symptoms, as well as some health issues that are correlated with surgical outcomes, ${ }^{31,50}$ were obtained for descriptive purposes and to ascertain homogeneity at baseline. General health status was assessed using Short Form Health Survey-20 (SF20), ${ }^{32}$ which provides scores ranging from 0 to 100 . In this study, the scores for pain were reversed so that for all domains higher scores corresponded to improved functioning for the specific domains at that moment.

\section{Primary Outcome Measurements}

Bodily pain, such as leg and back pain, was measured using the visual analog scale (VAS) while standing and walking. Functional disability was assessed using the Roland-Morris Disability Questionnaire (RMDQ), ${ }^{21,47,48}$ which consists of 24 physical limitations related to back pain (a score of 24 indicates severe physical disability), and the Oswestry Disability Index (ODI), ${ }^{16,17}$ which quantifies disability due to back problems (a score of 81-100 indicates being completely bedridden or patients heavily exaggerating their symptoms).

In addition to RMDQ and ODI, we evaluated the effect of surgery on symptoms by asking patients to what degree the leg and back symptoms, in general, were reduced after surgery using a 5-point Likert scale (symptoms were much reduced [scored as 1] through symptoms were much worse [scored as 5]). Symptoms that were much or somewhat reduced were considered clinically relevant and, in this study, referred to as a "marked reduction in symptoms." Moreover, patients were asked about their main types of symptoms before surgery (i.e., pain, numbness, tingling, lower-limb weakness, heaviness of the lower limbs, and other symptoms, specified further). The patient's general evaluation of treatment was assessed using a 7-point Likert scale, where answers varied from "I am fully recovered" (1) to "It is worse than ever" (7). Responses such as "complete" or "somewhat recovered" after surgery were considered good results and a surgical success.

\section{Secondary Outcomes}

Another important patient-reported outcome measurement was patient satisfaction, assessed using the 5-point Likert scale, where success was scored from "very successful, it helped completely" to "worse than before surgery." Patients were also asked if they would recommend the surgery to a friend with the same condition. Patients who reported that it was very successful or fairly successful and those who would recommend the procedure to a friend were classified as "overall satisfied."

Surgical and radiological data included the level that was operated on, length of surgery (from incision until closing), length of hospitalization, both intraoperative and postoperative complications (through 30 days after surgery), the radiological level of stenosis, the presence of degenerative spondylolisthesis (specified by level and grade), and the American Society of Anesthesiologists (ASA) grade.

\section{Statistical Analysis}

Sixty-three patients had to be included in each group in order to obtain sufficient statistical power and detect at least a $20 \%$ difference in postoperative pain scores (VAS) between surgical techniques (two-sided $\alpha=0.05$; power $=80 \%$ ). Based on our experiences, we expected a $65 \%$ response rate to the questionnaires, and therefore aimed to include a minimum of 193 patients.

Statistical analyses were performed using SPSS version 18.0 (SPSS Inc.). The means and standard deviations (continuous variables) and percentages (categorical variables) were calculated for both groups. Differences between treatment groups were analyzed using the unpaired Student $t$ test for continuous variables, or the chi-square test and Mann-Whitney test for categorical and nonparametric data. All values are presented as the mean $\pm \mathrm{SD}$, unless otherwise stated. When significant differences between primary outcomes occurred, regression models were used to describe the possible correlations with confounding factors. Linear regression was used to assess continuous variables (VAS, ODI, and RMDQ), and logistic regression was used to assess dichotomized variables (e.g., patient satisfaction, general patient evaluation, and symptom reduction). Confounding factors with a significance level $<0.010$ in the univariate analysis were analyzed using forward stepwise multivariate regression model based on their contributions to the differences in the likelihood ratios.

\section{Results}

\section{Patient Selection}

Of the 983 patients evaluated for study eligibility, 235 met the inclusion criteria and received a questionnaire. Figure 1 describes the inclusion trajectory that, in the end, resulted in the inclusion of 68 patients in the bilateral group and 107 patients in the unilateral group, thereby exceeding the required calculated sample size.

\section{Baseline Characteristics}

The mean age of the study population $(n=175)$ at surgery was $68 \pm 10$ years with a mean follow up of $14.2 \pm$ 6.4 months (range 3.3-27.4 months). Table 1 shows no demographic differences between the study groups, and the population was homogeneous in terms of the measured parameters, except for some SF-20 domains. Compared with the mean values of a large Dutch sample comprising patients between 65 and 69 years of age who were selected from the general population $(n=1090),{ }^{32}$ the current study population scored significantly lower on all SF-20 domains, thus indicating poorer general well-being (data not shown). Furthermore, there were no major differences in preoperative symptoms or comorbidities between groups.

\section{Intraoperative Data and Surgical Morbidity}

The mean surgical duration was significantly longer for bilaterally operated patients - 53 minutes (range 14-126 minutes) versus 42 minutes (range 20-70 minutes) ( $\mathrm{p}<$ 0.001 )-but patients in the unilateral group required longer hospitalizations on average (Table 2).

There were 14 procedure-related complications in 13 patients: 6 dural tears (3.4\%), 4 extradural hematomas (2.3\%), and 2 wound infections (1.1\%), and 1 patient had a dural tear and a postoperative extradural hematoma 
983 medical records were screened

557 in the unilateral group (57\%)

426 in the bilateral group ( $43 \%)$
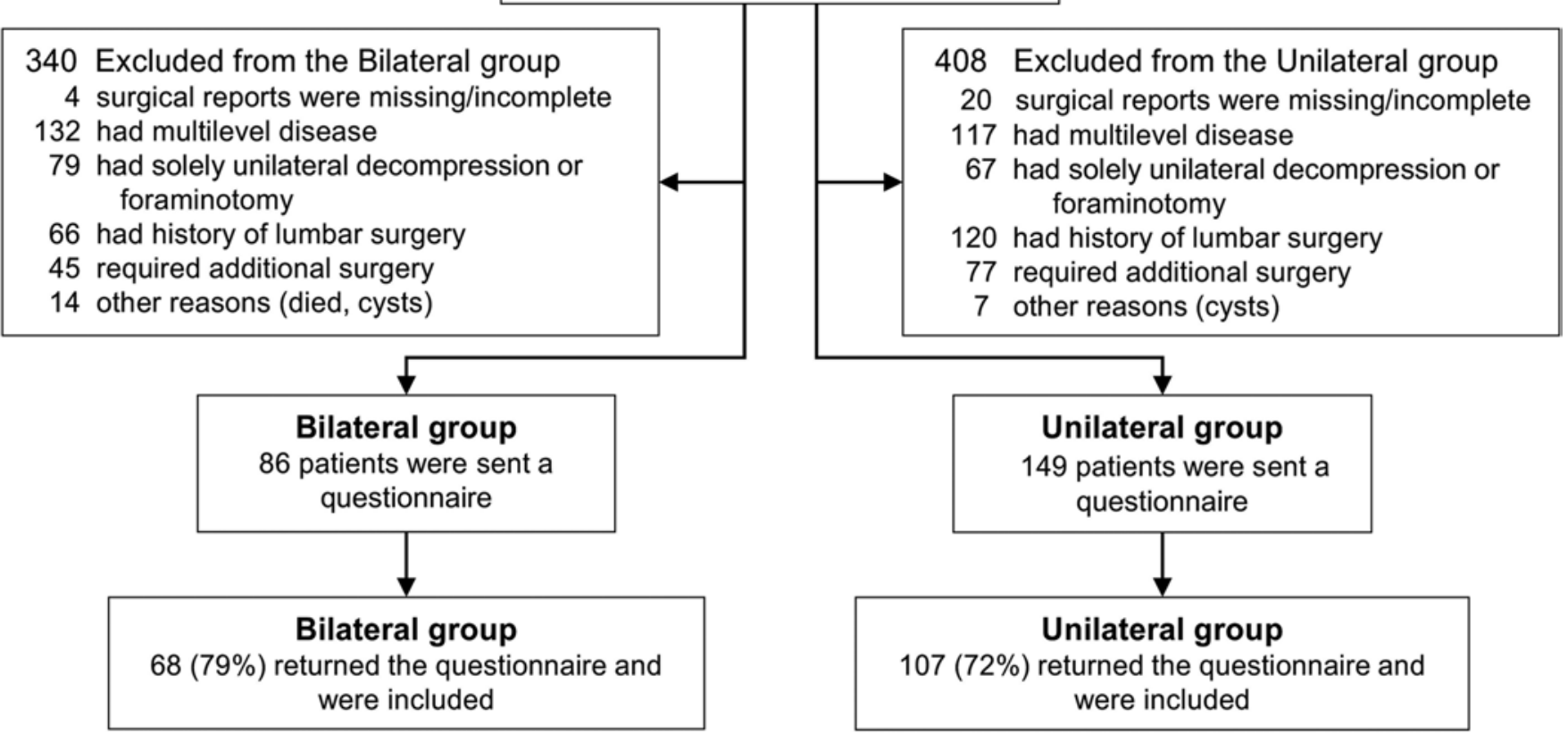

FIG. 1. Patient selection. Flow diagram showing the total number of medical records screened in terms of treatment codes, reasons for exclusion, and remaining number of patients eligible for study participation in both study groups.

(0.6\%). In most cases, dural tears led to obligatory bed rest and subsequently longer hospitalizations. All 5 symptomatic and MRI-confirmed extradural hematomas occurred in the bilateral group, 2 patients required reoperation, and 3 patients were successfully treated conservatively (Table 2). There were no perioperative deaths.

\section{Primary Outcome Evaluation}

The majority of patients (74.8\%) reported reduced back complaints; $58.9 \%$ of the patients noted much symptom reduction, $16 \%$ at least some reduction, and $25.2 \%$ reported poor results (i.e., no change in symptoms or symptoms became somewhat worse or much worse). With respect to leg symptoms, $80.6 \%$ of the patients reported marked reduction $(64.7 \%$ experienced much symptom reduction, and $15.9 \%$ reported some reduction). Both the bilateral and unilateral group showed a marked reduction in leg symptoms (not further specified); however, symptom reduction was more significant in the unilateral group than in the bilateral group $(85.4 \%$ and $73.1 \%$, respectively; $\mathrm{p}=$ 0.048 ) (Table 3). Of note, missing data $(1.1 \%)$ and patients who reported the absence of leg symptoms $(n=3,1.7 \%)$ or back symptoms $(\mathrm{n}=10,5.7 \%)$ preoperatively, and therefore also did not reported any symptoms postoperatively, were excluded from this analysis of the effects of surgery.

The overall postoperative ODI and RMDQ scores were low, indicating low levels of disability. In terms of the postoperative pain experienced by patients, the most common complaint was back pain while standing, followed by leg pain while walking. Although there seemed to be a trend toward better scores in the bilateral group, these differences with regard to ODI, RMDQ, and overall pain scores are limited and not statistically significant $(\mathrm{p}=$ $0.453,0.330$, and 0.338 , respectively) (Table 3 ). There was also no statistically significant difference between groups in terms of the patients' general treatment evaluations ( $p$ $=0.226)$.

\section{Patient Satisfaction}

Most patients considered the procedure to be very successful or fairly successful, and would also recommend their procedure to a friend (data not shown). In general, patients in the unilateral group were more satisfied than patients in the bilateral group ( $81.9 \%$ vs $70.6 \%, \mathrm{p}=0.082)$. Moreover, a higher percentage of patients in the unilateral group would give a positive recommendation (91.3\% vs $80.6 \%, \mathrm{p}=0.043$ ). After combining these 2 patient-reported outcome measures, the unilateral approach is considered significantly superior to the bilateral approach $(82.1 \%$ vs $69.1 \%, p=0.047)$ (Table 4$)$.

\section{Discussion}

Both the bilateral interlaminar approach for bilateral decompression, ${ }^{4,22,43,46,58,59,64}$ as well as the unilateral approach, ${ }^{11,14,22,26,40,41,43,51,55,62}$ have been extensively researched and have shown promising results. Most of these studies, however, were limited by the size of the study population and choice of intervention. In many instances, only the unilateral approach was investigated, mainly because it was the only procedure (besides standard laminectomy) performed at the clinic (surgeon 
TABLE 1. Baseline characteristics

\begin{tabular}{|c|c|c|c|}
\hline Parameter & Bilateral Group & Unilateral Group & p Value* \\
\hline \multicolumn{4}{|l|}{ Patient population \& demographic data } \\
\hline No. of patients & 68 & 107 & \\
\hline Mean follow-up period (mos \pm SD) & $14.9 \pm 6.6$ & $13.8 \pm 6.3$ & 0.297 \\
\hline Mean age at surgery (yrs \pm SD) & $68 \pm 9$ & $66 \pm 11$ & 0.250 \\
\hline Mean age at completing questionnaire (yrs \pm SD) & $69 \pm 9$ & $67 \pm 11$ & 0.224 \\
\hline Male sex $(\%)$ & 45.6 & 46.7 & 0.883 \\
\hline \multicolumn{4}{|l|}{ Home situation (\%) } \\
\hline Married & 70.6 & 70.5 & 0.764 \\
\hline Living alone & 19.4 & 21.9 & 0.694 \\
\hline Level of education $(\%) \dagger$ & & & 0.952 \\
\hline Low & 68.7 & 69.5 & \\
\hline Medium & 17.9 & 16.2 & \\
\hline High & 13.4 & 14.3 & \\
\hline Employment status (n [\%]) & & & 0.353 \\
\hline Employed $\geq 32$ hrs/wk & 11.9 & 11.8 & \\
\hline Employed <32 hrs/wk & 7.5 & 9.8 & \\
\hline Unemployed & 4.5 & 11.8 & \\
\hline Unfit for work & 4.5 & 7.8 & \\
\hline Retired & 71.6 & 58.8 & \\
\hline \multicolumn{4}{|l|}{ Preoperative symptoms \& current health status } \\
\hline Back symptoms present (\%) & 84.8 & 87.9 & 0.572 \\
\hline Symptoms present $\geq 12$ mos (\%) & 60.6 & 68.2 & 0.593 \\
\hline Leg symptoms present (\%) & 95.6 & 91.3 & 0.286 \\
\hline Symptoms present $\geq 12 \operatorname{mos}(\%)$ & 60.3 & 60.6 & 0.517 \\
\hline Most symptomatic leg (\%) & & & 0.128 \\
\hline Bilateral symptoms & 45.6 & 31.1 & \\
\hline Left leg > right leg & 29.4 & 41.7 & \\
\hline Right leg > left leg & 25.0 & 27.2 & \\
\hline \multicolumn{4}{|l|}{ Type of symptoms (\%) } \\
\hline Pain & 79.4 & 81.3 & 0.757 \\
\hline Numbness & 47.1 & 52.3 & 0.496 \\
\hline Tingling & 38.2 & 35.5 & 0.716 \\
\hline Weakness of lower limbs & 33.8 & 38.3 & 0.547 \\
\hline Heaviness of lower limbs & 27.9 & 24.3 & 0.591 \\
\hline Other & 26.5 & 18.7 & 0.224 \\
\hline Trouble walking due to cardiovascular or musculoskeletal disease (\%) & 29.9 & 34.6 & 0.518 \\
\hline Operated musculoskeletal apparatus (\%) & 37.3 & 43.0 & 0.458 \\
\hline Current smoker (\%) & 16.4 & 18.7 & 0.703 \\
\hline \multicolumn{4}{|l|}{ SF-20 (mean scores \pm SD) } \\
\hline Physical functioning & $51.5 \pm 35.0$ & $42.7 \pm 32.1$ & 0.090 \\
\hline Role functioning & $66.4 \pm 45.6$ & $49.5 \pm 47.3$ & 0.021 \\
\hline Social functioning & $78.2 \pm 27.4$ & $68.0 \pm 30.1$ & 0.026 \\
\hline Mental health & $79.5 \pm 15.5$ & $70.6 \pm 18.6$ & 0.001 \\
\hline Current health perceptions & $64.1 \pm 28.3$ & $54.9 \pm 26.3$ & 0.032 \\
\hline Pain§ & $54.5 \pm 31.7$ & $48.1 \pm 32.4$ & 0.205 \\
\hline
\end{tabular}


TABLE 1. Baseline characteristics (continued)

\begin{tabular}{|c|c|c|c|}
\hline Parameter & Bilateral Group & Unilateral Group & p Value \\
\hline Own health assessment $(\%)^{* *}$ & & & 0.399 \\
\hline Excellent & 15.2 & 6.7 & \\
\hline Very good & 13.6 & 13.5 & \\
\hline Good & 40.9 & 43.3 & \\
\hline Fair & 25.8 & 33.7 & \\
\hline Bad & 4.5 & 2.9 & \\
\hline \multicolumn{4}{|c|}{$\begin{array}{l}\text { * Values in boldface are statistically significant. } \\
\dagger \text { Categorized according to the Dutch educational classification system (http://www.nationaalkompas.nl/bevolking/scholing-en-opleiding/ } \\
\text { indeling-opleidingsniveau/). "No education" ( } n=2 ; 1.1 \% \text { ) was combined with the "low education" group. } \\
\text { † Other symptoms included trouble walking, blockage during walking, cramps, and instability. } \\
\text { § For readability, pain has been reversed, so that higher scores indicate less pain. This is a contradiction to the literature. } \\
\text { ** Refers to the first question in the SF-20: "In general, what would you say your health is...", followed by the } 5 \text { answer possibilities. }\end{array}$} \\
\hline
\end{tabular}

bias) or it was given more attention since it is theoretically considered a less invasive technique, given that only a 1 -sided interlaminar opening is created. In this retrospective study, we compared the currently available and frequently used minimally invasive techniques in 175 patients with single-level DLSS and evaluated if these techniques demonstrate equal outcomes in terms of postoperative pain, functional disability, symptom reduction, patient satisfaction, and certain surgical parameters.

\section{Primary Outcome Assessments}

On average, both treatment groups scored low on the functional disability and pain scales at 14 months after surgery, and more than $70 \%$ of the patients reported marked reduction in back and leg symptoms. These results are in accordance with various studies reporting improvement in functional disability and pain after surgery for DLSS. 5,6,11,14,38,41,49,51 There were no significant differences in disability (ODI, RMDQ) or leg and back pain (VAS) between treatment groups. However, somewhat surprisingly,

TABLE 2. Radiological data, intraoperative measurements, and postoperative care

\begin{tabular}{|c|c|c|c|}
\hline Parameter & Bilateral & Unilateral & p Value* \\
\hline ASA Class 3 (n [\%]) & $8(11.8)$ & $7(6.5)$ & 0.229 \\
\hline Spondylolisthesis present $(\mathrm{n}[\%]) \dagger$ & $10(14.7)$ & $20(19.2)$ & 0.445 \\
\hline Mean duration of surgery (min) & $52.6 \pm 18.3$ & $41.5 \pm 11.8$ & 0.000 \\
\hline Mean hospitalization (days) & $1.3 \pm 1.2$ & $2.1 \pm 1.1$ & 0.000 \\
\hline All complications (\%) & & & 0.069 \\
\hline Dural tear & 4.4 & 2.8 & \\
\hline Hematoma & 5.9 & 0 & \\
\hline Dural tear \& hematoma & 1.5 & 0 & \\
\hline Wound infection & 1.5 & 0.9 & \\
\hline Side of unilateral approach, left/right (\%) & NA & $58.9 / 41.1$ & \\
\hline Level operated $(\%)$ & & & 0.611 \\
\hline L2-3 & 2.9 & 7.5 & \\
\hline L3-4 & 32.4 & 33.6 & \\
\hline L4-5 & 63.2 & 57.9 & \\
\hline L5-6‡ & 1.5 & 0.9 & \\
\hline Level of stenosis (\%)§ & & & 0.589 \\
\hline L2-3 & 2.9 & 7.7 & \\
\hline L3-4 & 32.4 & 33.7 & \\
\hline L4-5 & 63.2 & 57.7 & \\
\hline L5-6‡ & 1.5 & 1 & \\
\hline
\end{tabular}

ASA = American Society of Anesthesiologists.

* Values in boldface are statistically significant.

† Stable Grade I spondylolisthesis was confirmed on flexion-extension radiography.

$\ddagger$ Extra lumbar vertebral body present and confirmed on radiography.

$\S$ Level of the most severe stenosis on MRI or CT. 
TABLE 3. Primary outcomes: functional disability and pain

\begin{tabular}{|c|c|c|c|}
\hline Parameter & Bilateral Group $(n=68)$ & Unilateral Group $(n=107)$ & p Value \\
\hline Mean ODI* & $20.3 \pm 18.5$ & $22.6 \pm 20.4$ & 0.453 \\
\hline Mean RMDQ† & $3.99 \pm 5.23$ & $4.80 \pm 5.51$ & 0.330 \\
\hline Mean VAS $\ddagger$ & $21.9 \pm 24.7$ & $25.6 \pm 24.8$ & 0.338 \\
\hline \multicolumn{4}{|l|}{ Overall } \\
\hline VAS back while walking & $21.3 \pm 26.7$ & $25.4 \pm 27.5$ & 0.327 \\
\hline VAS back while standing & $21.7 \pm 28.1$ & $27.9 \pm 28.8$ & 0.165 \\
\hline VAS legs while walking & $22.8 \pm 28.7$ & $26.2 \pm 28.2$ & 0.447 \\
\hline VAS legs while standing & $21.7 \pm 28.6$ & $23.3 \pm 26.2$ & 0.692 \\
\hline \multicolumn{4}{|l|}{ Effect of surgery on symptoms§ } \\
\hline Marked reduced back symptoms (\%) & 74.6 & 75.0 & 0.955 \\
\hline Marked reduced leg symptoms (\%) & 73.1 & 85.4 & 0.048 \\
\hline General patient evaluation (\%)** & & & 0.226 \\
\hline Good result & 72.1 & 80.0 & \\
\hline Poor result & 27.9 & 20.0 & \\
\hline \multicolumn{4}{|c|}{$\begin{array}{l}\text { Range ODI: 0-100; higher score corresponds with more disability. } \\
\text { t Range RMDQ: 0-24; higher score corresponds with more disability. } \\
\text { Range VAS: 0-100; higher score indicates more pain. } \\
\text { \& Reduced symptoms: symptoms were much reduced or somewhat reduced after surgery. }\end{array}$} \\
\hline
\end{tabular}

a significant difference was found in the percentage of patients who claimed a marked reduction in leg symptoms after surgery (e.g., pain, sensory disturbances, heavy legs, paresthesias). This is contrary to the findings of Thomé et al. who, in a prospective study that compared laminectomy, unilateral, and bilateral laminotomy, found less postoperative leg pain in the bilateral group in comparison with the unilateral group. ${ }^{58}$ More recently, Hong et al. ${ }^{22}$ also focused on single-level decompression and reported almost similar results to those in our studies, including no significant differences in the pain scores for the back and leg after a mean follow-up period of 49.3 months. The differences in leg pain that we detected were not related to the surgical procedure or any other clinical parameter included in the multivariate analysis.

Our results do not support the presumption that more back pain will develop in patients who undergo the bilateral approach due to the more extensive bilateral stripping of the spinal muscles, as suggested by several authors. $3,24,33,54$ The present study also does not support the somewhat unexpected results reported by Thomé et al., that patients who undergo unilateral surgeries develop more back pain. ${ }^{58} \mathrm{In}$ our study, both groups reported marked reduction in back symptoms, and there were no significant differences between groups.

\section{Patient Satisfaction and General Evaluations}

Both techniques showed very good results on important patient-reported outcome measures, with high patient satisfaction rates, and $72.1 \%$ and $80.0 \%$ of patients in the bilateral and unilateral groups reporting good recovery after surgery, respectively (Table 3). These numbers are higher than the success rates for laminectomy, which vary in the current literature between $50 \%$ and $70 \% \%^{12,25,27,30,45,58,60}$ with satisfaction rates between $55 \%$ and $73 \%,{ }^{6,7,29,58,63}$ but are similar to the results of unilateral laminotomy studies (successful results in more than $80 \%$ of patients, and satisfaction rates ranging from $74.4 \%$ to $97 \%)^{40,55,58,62}$ and bilateral series (good results reported in $68 \%$ to $90 \%$ of cases). ${ }^{4,34,42,57,59,64}$ Interestingly, we did find a difference in patient satisfaction, as significantly more patients in the unilateral group were satisfied overall in comparison with the bilaterally operated patients $(82.1 \%$ vs $69.1 \%$, p $=0.047)$. This is in contrast to results reported by Thomé et al. who investigated almost identical techniques (except they also preserved the supra- and interspinous ligaments while using the bilateral technique). In their study, the bilateral approach was found to be preferable to the unilateral technique in terms of overall success (80\% vs $70 \%$ ) and patient satisfaction (97.3\% vs $74.4 \%) .{ }^{58}$ Again, we did not identify any parameter in the multivariate analysis that explains this difference. Presumably other external factors (e.g., the surgeon or hospital) play more important roles in the patient's perception of the whole procedure and degree of satisfaction.

TABLE 4. Secondary outcomes: patient satisfaction, general evaluations, and symptom reduction

\begin{tabular}{lccc}
\hline \multicolumn{1}{c}{ Parameter } & $\begin{array}{c}\text { Bilateral } \\
\text { Group } \\
(\mathrm{n}=68)\end{array}$ & $\begin{array}{c}\text { Unilateral } \\
\text { Group } \\
(\mathrm{n}=106)\end{array}$ & $\mathrm{p} \mathrm{Value^{* }}$ \\
\hline Satisfied w/ surgery (\%) $\dagger$ & 70.6 & 81.9 & 0.082 \\
\hline Would recommend it to a friend $(\%)$ & 80.6 & 91.3 & $\mathbf{0 . 0 4 3}$ \\
\hline Overall satisfied (\%) $\ddagger$ & 69.1 & 82.1 & $\mathbf{0 . 0 4 7}$ \\
\hline
\end{tabular}

* Values in boldface are statistically significant.

$\dagger$ Surgery was very successful: it helped completely or was considered fairly successful.

$\ddagger$ Surgery was very successful or fairly successful, and those who provided a positive recommendation to a friend. 


\section{Surgical Parameters}

The surgical duration has been reported to range from 75 to 119 minutes for unilateral laminotomy $y^{14,22,26,43,55,58}$ to 90 to 117 minutes for bilateral laminotomy. ${ }^{22,43,58}$ In most of these publications, multilevel decompression was also performed, which can explain the high averages in comparison with our findings. Hong et al. only addressed single-level L4-5 stenosis and reported an average operating time of 63 minutes for the unilateral approach versus 103 minutes for the bilateral laminotomy. ${ }^{22}$

It has been suggested that due to the limited visual field available while performing unilateral laminotomy and contralateral decompression, the chance of iatrogenic dural tears is relatively high and the contralateral side is more prone to symptomatic residual stenosis. ${ }^{11,22,46}$ Surprisingly, and in contrast with other studies, ${ }^{14,34,40,58}$ we found that dural tears and postoperative hematomas occurred more often in the bilateral group. Applying logistic regression analysis, no surgeon- or patient-related factors significantly accounted for these differences. Furthermore, our clinical findings do not indicate a higher chance of symptomatic residual stenosis in the patients who received unilateral laminotomy. In fact, there was an even higher percentage of patients in the unilateral group who reported marked reduction, and therefore we carefully conclude that if there was any residual stenosis, it did not result in a worse clinical outcome. Moreover, we argue that our results support the claim that using the unilateral approach to treat bilateral decompression is as safe and effective as the bilateral approach.

\section{Study Limitations}

The retrospective design of this study yields some limitations-especially missing preoperative VAS, ODI, and RMDQ scores-which make it impossible to adequately compare postoperative status and baseline. Furthermore, this design cannot properly interpret confounding factors and adjust for outcomes. By performing these procedures at different clinics instead of running a randomized controlled trial, surgeon- and hospital-related bias cannot be excluded and might even explain the differences in patient satisfaction.

Some of these limitations would have been avoided if the data on the operated patients had been collected from a national registry. Therefore, we strongly support the efforts already made by the Dutch Spine Society to introduce such a registry in the Netherlands. In our opinion, evaluating the safety and efficacy of different (or new) procedures could benefit from such a registry.

\section{Conclusions}

Despite some important limitations, this study of 175 patients provides a good comparison of the unilateral and bilateral interlaminar approaches, with the goal of achieving bilateral decompression in a common clinical setting. We found that both surgical techniques are safe and effective treatment options for single-level DLSS, demonstrating satisfactory postoperative results in terms of functional disability, pain, and patient satisfaction. Based on our findings, no strong recommendations for either the bilateral or unilateral approach can be made. The marked reduction in leg symptoms and overall patient satisfaction significantly favor using the unilateral approach for reasons that cannot be directly explained by the type of surgery or other parameters measured in this study. Patient satisfaction can be influenced by numerous factors, most of them external. To better understand the differences between the two treatment groups in terms of patient satisfaction and clinically notable reduction in leg symptoms after surgery, a randomized trial should be used to prevent a surgeonand hospital-related bias. Although a randomized controlled trial would provide a higher level of evidence than the current design, we strongly doubt such a trial would be of clinical significance and profitable, because our results show very satisfactory and almost comparable results between the study groups in terms of important primary patient-related outcomes in a common surgical practice.

\section{Key Points}

- The overall results were satisfactory. Both surgical techniques have proven to be safe and effective, with short operating times, short hospital stays, and only a few complications.

- There was no difference in functional disability (ODI and RMDQ) or pain (VAS) between the two treatment groups. Leg and back symptoms were reduced in $80 \%$ and $75 \%$ of all the unilaterally and bilaterally treated patients, respectively.

- Significantly more patients who were treated using the unilateral approach were overall satisfied and demonstrated markedly reduced leg symptoms (not further specified) after surgery. The multivariate analysis showed no relationship between the surgical procedure and any other clinical parameter. Presumably, other external factors (e.g., surgeon or hospital) play more important roles in the patient's perception of the whole procedure and degree of satisfaction.

- Based on the results of this study - which are very satisfactory in both treatment groups-we strongly doubt if a future "costly" randomized controlled trial would yield added value to our retrospective results.

\section{References}

1. Airaksinen O, Herno A, Kaukanen E, Saari T, Sihvonen T, Suomalainen O: Density of lumbar muscles 4 years after decompressive spinal surgery. Eur Spine J 5:193-197, 1996

2. Amundsen T, Weber H, Nordal HJ, Magnaes B, Abdelnoor M, Lilleâs F: Lumbar spinal stenosis: conservative or surgical management? A prospective 10-year study. Spine (Phila Pa 1976) 25:1424-1436, 2000

3. Arts MP, Nieborg A, Brand R, Peul WC: Serum creatine phosphokinase as an indicator of muscle injury after various spinal and nonspinal surgical procedures. J Neurosurg Spine 7:282-286, 2007

4. Aryanpur J, Ducker T: Multilevel lumbar laminotomies: an alternative to laminectomy in the treatment of lumbar stenosis. Neurosurgery 26:429-433, 1990

5. Atlas SJ, Deyo RA, Keller RB, Chapin AM, Patrick DL, Long JM, et al: The Maine Lumbar Spine Study, Part III. 1-year outcomes of surgical and nonsurgical management of lumbar spinal stenosis. Spine (Phila Pa 1976) 21:1787-1795, 1996 
6. Atlas SJ, Keller RB, Robson D, Deyo RA, Singer DE: Surgical and nonsurgical management of lumbar spinal stenosis: four-year outcomes from the Maine Lumbar Spine Study. Spine (Phila Pa 1976) 25:556-562, 2000

7. Atlas SJ, Keller RB, Wu YA, Deyo RA, Singer DE: Longterm outcomes of surgical and nonsurgical management of lumbar spinal stenosis: 8 to 10 year results from the Maine Lumbar Spine Study. Spine (Phila Pa 1976) 30:936-943, 2005

8. Benoist M: The natural history of lumbar degenerative spinal stenosis. Joint Bone Spine 69:450-457, 2002

9. Benz RJ, Garfin SR: Current techniques of decompression of the lumbar spine. Clin Orthop Relat Res (384):75-81, 2001

10. Birkmeyer NJ, Weinstein JN, Tosteson AN, Tosteson TD, Skinner JS, Lurie JD, et al: Design of the spine patient outcomes research trial (SPORT). Spine (Phila Pa 1976) 27:1361-1372, 2002

11. Cavuşoğlu H, Kaya RA, Türkmenoglu ON, Tuncer C, Colak I, Aydin Y: Midterm outcome after unilateral approach for bilateral decompression of lumbar spinal stenosis: 5-year prospective study. Eur Spine J 16:2133-2142, 2007

12. Chou R, Baisden J, Carragee EJ, Resnick DK, Shaffer WO, Loeser JD: Surgery for low back pain: a review of the evidence for an American Pain Society Clinical Practice Guideline. Spine (Phila Pa 1976) 34:1094-1109, 2009

13. Ciol MA, Deyo RA, Howell E, Kreif S: An assessment of surgery for spinal stenosis: time trends, geographic variations, complications, and reoperations. J Am Geriatr Soc 44:285-290, 1996

14. Costa F, Sassi M, Cardia A, Ortolina A, De Santis A, Luccarell G, et al: Degenerative lumbar spinal stenosis: analysis of results in a series of 374 patients treated with unilateral laminotomy for bilateral microdecompression. J Neurosurg Spine 7:579-586, 2007

15. Deyo RA, Ciol MA, Cherkin DC, Loeser JD, Bigos SJ: Lumbar spinal fusion. A cohort study of complications, reoperations, and resource use in the Medicare population. Spine (Phila Pa 1976) 18:1463-1470, 1993

16. Fairbank JC, Couper J, Davies JB, O'Brien JP: The Oswestry low back pain disability questionnaire. Physiotherapy 66:271-273, 1980

17. Fairbank JC, Pynsent PB: The Oswestry Disability Index. Spine (Phila Pa 1976) 25:2940-2952, 2000

18. Fanuele JC, Birkmeyer NJ, Abdu WA, Tosteson TD, Weinstein JN: The impact of spinal problems on the health status of patients: have we underestimated the effect? Spine (Phila Pa 1976) 25:1509-1514, 2000

19. Fritz JM, Erhard RE, Vignovic M: A nonsurgical treatment approach for patients with lumbar spinal stenosis. Phys Ther 77:962-973, 1997

20. Genevay S, Atlas SJ: Lumbar spinal stenosis. Best Pract Res Clin Rheumatol 24:253-265, 2010

21. Gommans IHB, Koes BW, van Tulder MW: Validiteit en responsiviteit nederlandstalige roland disability questionnaire. vragenlijst naar functionele status bij patienten met lage rugpijn. Nederlands Tijdschrift Voor Fysiotherapie 107:28-33, 1997

22. Hong SW, Choi KY, Ahn Y, Baek OK, Wang JC, Lee SH, et al: A comparison of unilateral and bilateral laminotomies for decompression of L4-L5 spinal stenosis. Spine (Phila Pa 1976) 36:E172-E178, 2011

23. Hopp E, Tsou PM: Postdecompression lumbar instability. Clin Orthop Relat Res 227:143-151, 1988

24. Huang TJ, Hsu RW, Li YY, Cheng CC: Less systemic cytokine response in patients following microendoscopic versus open lumbar discectomy. J Orthop Res 23:406-411, 2005

25. Iguchi T, Kurihara A, Nakayama J, Sato K, Kurosaka M, Yamasaki K: Minimum 10-year outcome of decompressive laminectomy for degenerative lumbar spinal stenosis. Spine (Phila Pa 1976) 25:1754-1759, 2000
26. Iwatsuki K, Yoshimine T, Aoki M: Bilateral interlaminar fenestration and unroofing for the decompression of nerve roots by using a unilateral approach in lumbar canal stenosis. Surg Neurol 68:487-492, 2007

27. Javid MJ, Hadar EJ: Long-term follow-up review of patients who underwent laminectomy for lumbar stenosis: a prospective study. J Neurosurg 89:1-7, 1998

28. Johnsson KE, Willner S, Johnsson K: Postoperative instability after decompression for lumbar spinal stenosis. Spine (Phila Pa 1976) 11:107-110, 1986

29. Katz JN, Lipson SJ, Brick GW, Grobler LJ, Weinstein JN, Fossel AH, et al: Clinical correlates of patient satisfaction after laminectomy for degenerative lumbar spinal stenosis. Spine (Phila Pa 1976) 20:1155-1160, 1995

30. Katz JN, Lipson SJ, Chang LC, Levine SA, Fossel AH, Liang $\mathrm{MH}$ : Seven- to 10-year outcome of decompressive surgery for degenerative lumbar spinal stenosis. Spine (Phila Pa 1976) 21:92-98, 1996

31. Katz JN, Stucki G, Lipson SJ, Fossel AH, Grobler LJ, Weinstein JN: Predictors of surgical outcome in degenerative lumbar spinal stenosis. Spine (Phila Pa 1976) 24:2229-2233, 1999

32. Kempen GIJM, Brilman EI, Heyink JW, Ormel J: Het meten van de algemene gezondheidstoestand met de MOS shortform general health survey (SF-20), een handleiding. Groningen, The Netherlands: Noordelijk Centrum Voor Gezondheidsvraagstukken, 1995

33. Kim K, Isu T, Sugawara A, Matsumoto R, Isobe M: Comparison of the effect of 3 different approaches to the lumbar spinal canal on postoperative paraspinal muscle damage. Surg Neurol 69:109-113, 2008

34. Kleeman TJ, Hiscoe AC, Berg EE: Patient outcomes after minimally destabilizing lumbar stenosis decompression: the "port-hole" technique. Spine (Phila Pa 1976) 25:865-870, 2000

35. Lee CK: Lumbar spinal instability (olisthesis) after extensive posterior spinal decompression. Spine (Phila Pa 1976) 8:429-433, 1983

36. Lipson SJ: Spinal-fusion surgery - advances and concerns. N Engl J Med 350:643-644, 2004

37. Majid K, Fischgrund JS: Degenerative lumbar spondylolisthesis: trends in management. J Am Acad Orthop Surg 16:208-215, 2008

38. Malmivaara A, Slätis P, Heliövaara M, Sainio P, Kinnunen $\mathrm{H}$, Kankare J, et al: Surgical or nonoperative treatment for lumbar spinal stenosis? A randomized controlled trial. Spine (Phila Pa 1976) 32:1-8, 2007

39. Mayer TG, Vanharanta H, Gatchel RJ, Mooney V, Barnes D, Judge L, et al: Comparison of CT scan muscle measurements and isokinetic trunk strength in postoperative patients. Spine (Phila Pa 1976) 14:33-36, 1989

40. Morgalla MH, Noak N, Merkle M, Tatagiba MS: Lumbar spinal stenosis in elderly patients: is a unilateral microsurgical approach sufficient for decompression? J Neurosurg Spine 14:305-312, 2011

41. Müslüman AM, Cansever T, Yılmaz A, Çavuşoğlu H, Yüce İ, Aydın Y: Midterm outcome after a microsurgical unilateral approach for bilateral decompression of lumbar degenerative spondylolisthesis. J Neurosurg Spine 16:68-76, 2012

42. Nakai O, Ookawa A, Yamaura I: Long-term roentgenographic and functional changes in patients who were treated with wide fenestration for central lumbar stenosis. J Bone Joint Surg Am 73:1184-1191, 1991

43. Nakanishi K, Tanaka N, Fujimoto Y, Okuda T, Kamei N, Nakamae T, et al: Medium-term clinical results of microsurgical lumbar flavectomy that preserves facet joints in cases of lumbar degenerative spondylolisthesis: Comparison of bilateral laminotomy with bilateral decompression by a unilateral approach. J Spinal Disord Tech 26:351-358, 2012 
44. Patrick DL, Deyo RA, Atlas SJ, Singer DE, Chapin A, Keller RB: Assessing health-related quality of life in patients with sciatica. Spine (Phila Pa 1976) 20:1899-1909, 1995

45. Postacchini F: Surgical management of lumbar spinal stenosis. Spine (Phila Pa 1976) 24:1043-1047, 1999

46. Postacchini F, Cinotti G, Perugia D, Gumina S: The surgical treatment of central lumbar stenosis. Multiple laminotomy compared with total laminectomy. J Bone Joint Surg Br 75:386-392, 1993

47. Roland M, Morris R: A study of the natural history of back pain. Part I: development of a reliable and sensitive measure of disability in low-back pain. Spine (Phila Pa 1976) 8:141144,1983

48. Roland M, Morris R: A study of the natural history of lowback pain. Part II: development of guidelines for trials of treatment in primary care. Spine (Phila Pa 1976) 8:145-150, 1983

49. Rosen DS, O’Toole JE, Eichholz KM, Hrubes M, Huo D, Sandhu FA, et al: Minimally invasive lumbar spinal decompression in the elderly: outcomes of 50 patients aged 75 years and older. Neurosurgery 60:503-510, 2007

50. Sandén B, Försth P, Michaëlsson K: Smokers show less improvement than nonsmokers two years after surgery for lumbar spinal stenosis: a study of 4555 patients from the Swedish spine register. Spine (Phila Pa 1976) 36:1059-1064, 2011

51. Sasai K, Umeda M, Maruyama T, Wakabayashi E, Iida H: Microsurgical bilateral decompression via a unilateral approach for lumbar spinal canal stenosis including degenerative spondylolisthesis. J Neurosurg Spine 9:554-559, 2008

52. Shenkin HA, Hash CJ: Spondylolisthesis after multiple bilateral laminectomies and facetectomies for lumbar spondylosis. Follow-up review. J Neurosurg 50:45-47, 1979

53. Siebert E, Prüss H, Klingebiel R, Failli V, Einhäupl KM, Schwab JM: Lumbar spinal stenosis: syndrome, diagnostics and treatment. Nat Rev Neurol 5:392-403, 2009

54. Sihvonen T, Herno A, Paljärvi L, Airaksinen O, Partanen $\mathrm{J}$, Tapaninaho A: Local denervation atrophy of paraspinal muscles in postoperative failed back syndrome. Spine (Phila Pa 1976) 18:575-581, 1993

55. Spetzger U, Bertalanffy H, Reinges MH, Gilsbach JM: Unilateral laminotomy for bilateral decompression of lumbar spinal stenosis. Part II: Clinical experiences. Acta Neurochir (Wien) 139:397-403, 1997

56. Taylor VM, Deyo RA, Cherkin DC, Kreuter W: Low back pain hospitalization. Recent United States trends and regional variations. Spine (Phila Pa 1976) 19:1207-1213, 1994

57. Thomas NW, Rea GL, Pikul BK, Mervis LJ, Irsik R, Mc-
Gregor JM: Quantitative outcome and radiographic comparisons between laminectomy and laminotomy in the treatment of acquired lumbar stenosis. Neurosurgery 41:567-575, 1997

58. Thomé C, Zevgaridis D, Leheta O, Bäzner H, Pöckler-Schöniger $\mathrm{C}$, Wöhrle J, et al: Outcome after less-invasive decompression of lumbar spinal stenosis: a randomized comparison of unilateral laminotomy, bilateral laminotomy, and laminectomy. J Neurosurg Spine 3:129-141, 2005

59. Tsai RY, Yang RS, Bray RS Jr: Microscopic laminotomies for degenerative lumbar spinal stenosis. J Spinal Disord 11:389-394, 1998

60. Turner JA, Ersek M, Herron L, Deyo R: Surgery for lumbar spinal stenosis. Attempted meta-analysis of the literature. Spine (Phila Pa 1976) 17:1-8, 1992

61. Vogt MT, Cawthon PM, Kang JD, Donaldson WF, Cauley JA, Nevitt MC: Prevalence of symptoms of cervical and lumbar stenosis among participants in the Osteoporotic Fractures in Men Study. Spine (Phila Pa 1976) 31:1445-1451, 2006

62. Weiner BK, Walker M, Brower RS, McCulloch JA: Microdecompression for lumbar spinal canal stenosis. Spine (Phila Pa 1976) 24:2268-2272, 1999

63. Weinstein JN, Tosteson TD, Lurie JD, Tosteson AN, Blood E, Hanscom B, et al: Surgical versus nonsurgical therapy for lumbar spinal stenosis. N Engl J Med 358:794-810, 2008

64. Young S, Veerapen R, O'Laoire SA: Relief of lumbar canal stenosis using multilevel subarticular fenestrations as an alternative to wide laminectomy: preliminary report. Neurosurgery 23:628-633, 1988

\section{Author Contributions}

Conception and design: all authors. Acquisition of data: den Boogert. Analysis and interpretation of data: all authors. Drafting the article: den Boogert. Critically revising the article: all authors. Reviewed submitted version of manuscript: all authors. Approved the final version of the manuscript on behalf of all authors: Kuijlen. Statistical analysis: den Boogert, Keers. Study supervision: Kuijlen, Keers, Oterdoom.

\section{Correspondence}

Jos M. A. Kuijlen, Department of Neurosurgery, University Medical Center Groningen, P.O. Box 30.001, 9700 RB Groningen, The Netherlands. email: j.m.a.kuijlen@umcg.nl. 